\title{
Exhaust Waste Heat Recovery of I. C. Engine by Thermoelectric Generator
}

\author{
S. V. Chavan \\ Department of Mechanical Engineering \\ N. K. Orchid College of Engineering and Technology, Solapur, Maharashtra, India \\ S. S. Kale \\ Department of Mechanical Engineering \\ N. K. Orchid College of Engineering and Technology, Solapur, Maharashtra, India \\ Dr. B. K. Sonage \\ Department of Mechanical Engineering \\ N. K. Orchid College of Engineering and Technology, Solapur, Maharashtra, India
}

\begin{abstract}
A major part of the heat supplied in an internal combustion engine is not realized as work output, but dumped into the atmosphere as waste heat. If this waste heat energy is tapped and converted into usable energy, the overall efficiency of an engine can be improved. The percentage of energy rejected to the environment through exhaust gas which can be potentially recovered is approximately $30-40 \%$ of the energy supplied by the fuel depending on engine load. Thermoelectric modules which are used as thermoelectric generators are solid state devices that are used to convert thermal energy from a temperature gradient to electrical energy and it works on basic principle of Seebeck effect. This paper demonstrates the potential of thermoelectric generation. Also, studied the performance factors of engine with and without thermoelectric generator. The conversion efficiency of thermoelectric generator is about $\mathbf{8 \%}$. Also, several main characteristics of the different structures proposed for the thermoelectric generators (TEGs) will be compared. In the review included in this paper, it would be useful to update the potential of thermoelectric generation in the automobile industry nowadays. The results presented can be considered as references of the minimum goals to be reached.
\end{abstract}

Keywords -Waste heat, seebeck effect, thermoelectric modules, thermoelectric generator

\section{INTRODUCTION}

A thermoelectric power generator is a solid state device that provides direct energy conversion from thermal energy (heat) due to a temperature gradient into electrical energy based on "Seebeck effect". The thermoelectric power cycle, with charge carriers (electrons) serving as the working fluid, follows the fundamental laws of thermodynamics and intimately resembles the power cycle of a conventional heat engine. The major drawback of thermoelectric power generator is their relatively low conversion efficiency (typically 8\%).

The exhaust waste heat recovery of I. C. Engine by Thermoelectric generator in this project we studied source of waste heat i.e diesel engine. We have been checked the exhaust temperature range of available waste heat source. After checking the temperature range of waste heat source we studied different waste heat recovery systems. Then we selected thermoelectric generator system to recover the present heat source. Also we have studied effect of thermoelectric generator on engine performance.

\section{THERMOELECTRIC GENERATOR}

\section{A. Basic concept of Thermoelectric generator -}

The basic theory and operation of thermoelectric based systems have been developed for many years. Thermoelectric power generation is based on a phenomenon called "Seebeck effect" discovered by Thomas Seebeck in 1821. When a temperature difference is established between the hot and cold junctions of two dissimilar materials (metals or semiconductors) a voltage is generated, i.e., Seebeck voltage. In fact, this phenomenon is applied to thermocouples that are extensively used for temperature measurements. Based on this Seebeck effect, thermoelectric devices can act as electrical power generators. 
A schematic diagram of a simple thermoelectric power generator operating based on Seebeck effect is shown in Fig.1, heat is transferred at a rate of QH from a high-temperature heat source maintained at $T H$ to the hot junction, and it is rejected at a rate of $Q L$ to a low-temperature sink maintained at $T \mathrm{~L}$ from the cold junction. Based on Seebeck effect, the heat supplied at the hot junction causes an electric current to flow in the circuit and electrical power is produced. Using the first-law of thermodynamics (energy conservation principle) the difference between $Q H$ and $Q L$ is the electrical power output We. It should be noted that this power cycle intimately resembles the power cycle of a heat engine (Carnot engine), thus in this respect a thermoelectric power generator can be considered as a unique heat engine [1].

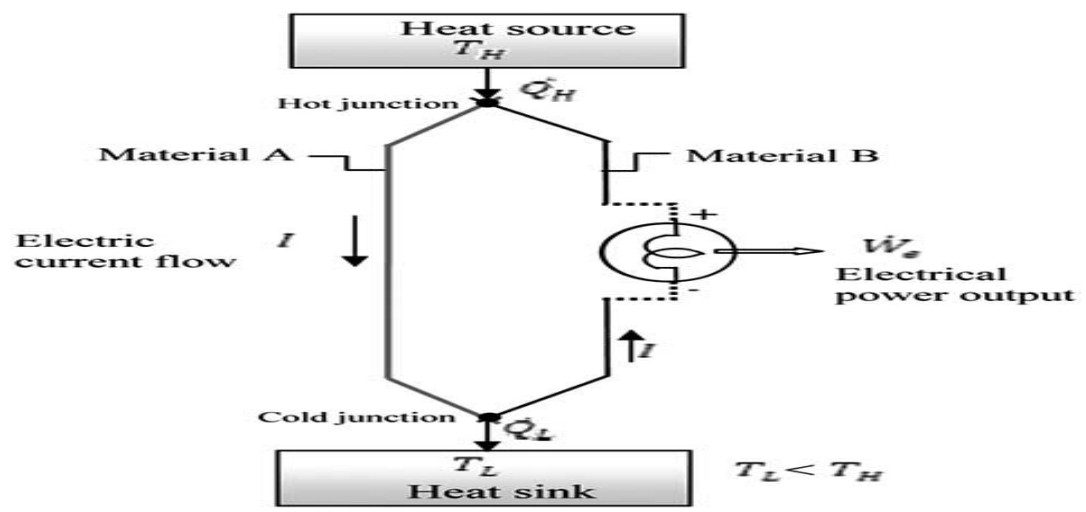

Figure1. Basic concept of a simple thermoelectric power generator operating based on Seebeck effect [1]

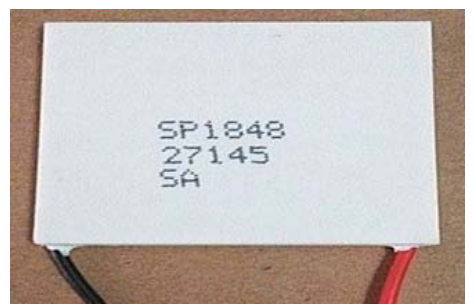

Figure2. Theromelectric module

\section{B. Thermoelectric generator system -}

Thermoelectric generator system is shown in following figure 3. Six TEG modules are fabricated in heat exchanger. The hot exhaust gas from engine is passed from one end and cold water is passed from other end, so temperature difference occurs and voltage is generated. Thermocouples and rotameter is provided to measure the temperature and cooling water flow rate. Cooling water is circulated by $0.5 \mathrm{HP}$ centrifugal pump.

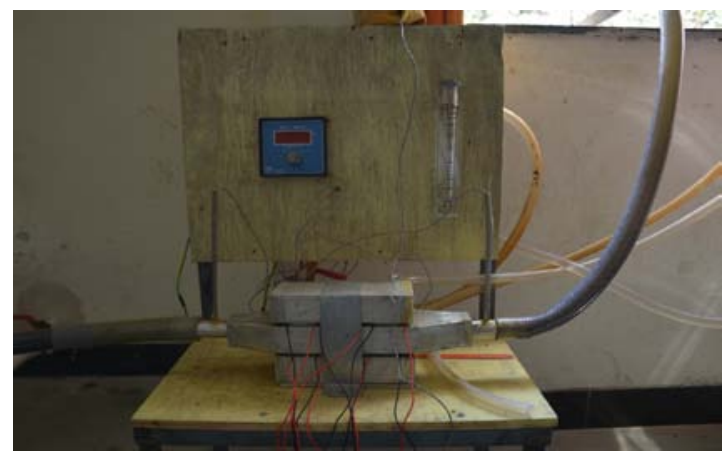

Figure3. Thermoelectric generator system 


\section{EXPERIMENT AND RESULT}

The heat exchangers are assembled with the sandwich arrangement of thermoelectric modules between them. Before assembly the thermal grease is applied on both the surfaces of TEG modules to enhance the heat transfer. Ceramic pads are inserted between the exchangers for insulation for the area not covered by modules. Thermocouples (KType) are connected along with the display for temperature measurement.

After successful assembly of heat exchangers, TEG System is attached on a 1 cylinder, 4 stroke, and Diesel Engine test rig. Experimental Setup is ready to take sets of trials at different engine speed. As a load on system, LED load bank is used. Using the thermocouples; temperatures at 5 sections are measured on Digital temperature indicator. Then voltage \& current at various engine speeds are measured on Digital multimeter.

\section{Performance Evaluation}

Calculations for efficiency of Thermo-electric Generator

1.Mass flow rate of exhaust gas $\left(\mathrm{m}_{\mathrm{g}}\right)$

Cross sectional area of exhaust gas pipe $=\frac{\prod_{d^{2}}}{4}=\underset{\times 0.035^{2}}{\prod}=9.621 \times 10^{-4} \mathrm{~m}^{2}$

Velocity of exhaust gas $=15.8 \mathrm{~m} / \mathrm{s}$

Flow rate of exhaust gas $=$ Area $\times$ Velocity $=9.621 \times 10^{-4} \times 15.8$

Density of Exhaust gas $=0.900 \mathrm{~kg} / \mathrm{m}^{3}$

$$
=0.01520 \mathrm{~m}^{3} / \mathrm{sec}
$$

Mass flow rate of exhaust gas $=$ Flow rate $\times$ Density

$$
\begin{aligned}
& =0.01520 \times 0.900 \\
\mathrm{~m}_{\mathrm{g}} & =0.01368 \mathrm{~kg} / \mathrm{sec}
\end{aligned}
$$

2. Specific heat of exhaust gas $\mathrm{C}_{\mathrm{pg}}=1 \mathrm{KJ} / \mathrm{Kg} . \mathrm{k}$

3. Heat supplied by the exhaust gas $=\mathrm{m}_{\mathrm{g}} \mathrm{c}_{\mathrm{pg}} \Delta \mathrm{T}$

$$
\begin{aligned}
& =\mathrm{m}_{\mathrm{g}} \mathrm{C}_{\mathrm{pg}}\left(\mathrm{T}_{1}-\mathrm{T}_{2}\right) \\
& =0.01368 \times 1 \times(135-120) \\
& =0.0 .2052 \mathrm{Kw} \\
& =205.2 \mathrm{~W}
\end{aligned}
$$

4. Electrical Power Output $=\mathrm{V} \times \mathrm{I}$

$$
\begin{aligned}
& =12.2 \times 1.4 \\
& =17.08 \mathrm{~W}
\end{aligned}
$$

Electrical Power Output

5. Efficiency of Thermoelectric Generator =

Heat Supplied by the exhaust gas

$$
=8.32 \%
$$

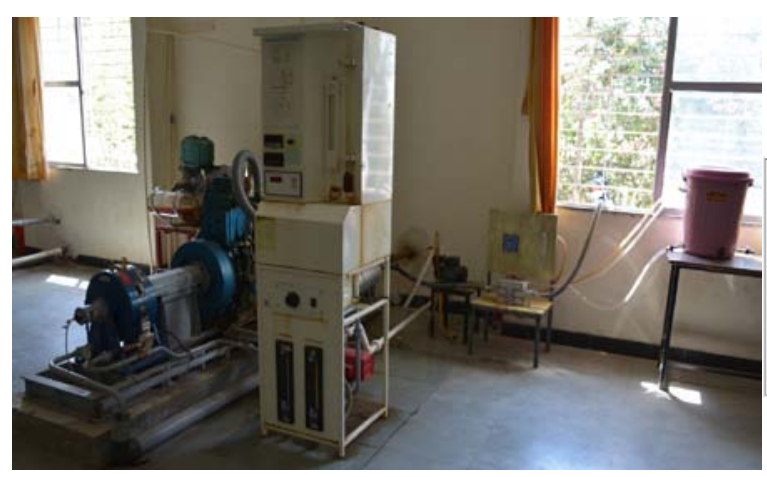

(a)

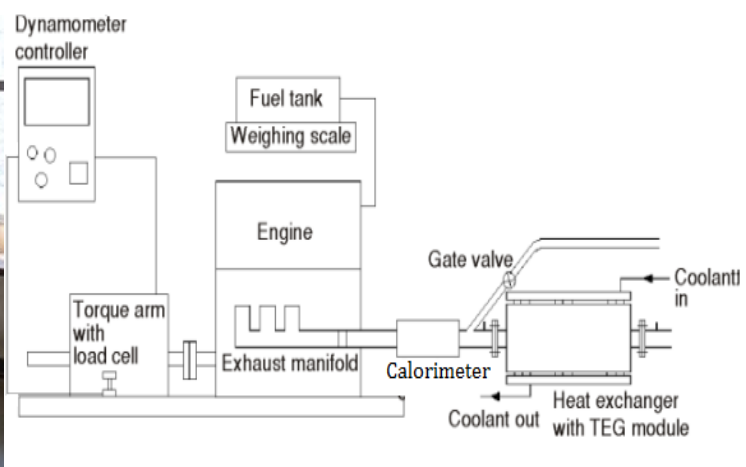

(b)

Figure 4. (a) Experimental setup (b) Schematic diagram of experimental setup 


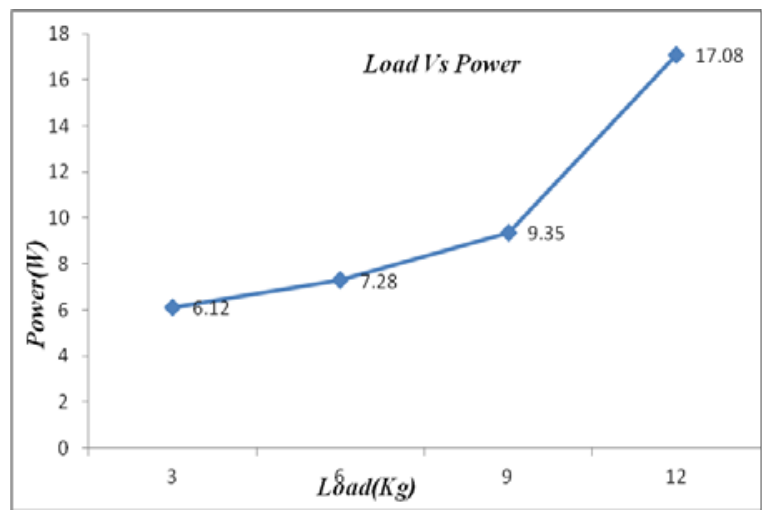

(a)

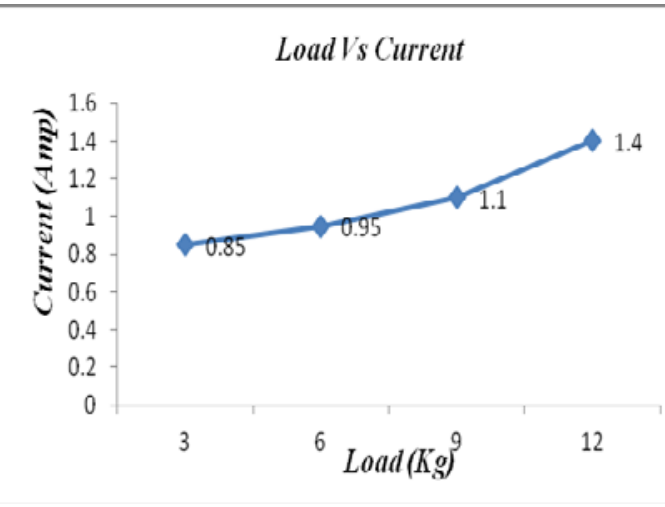

(c)

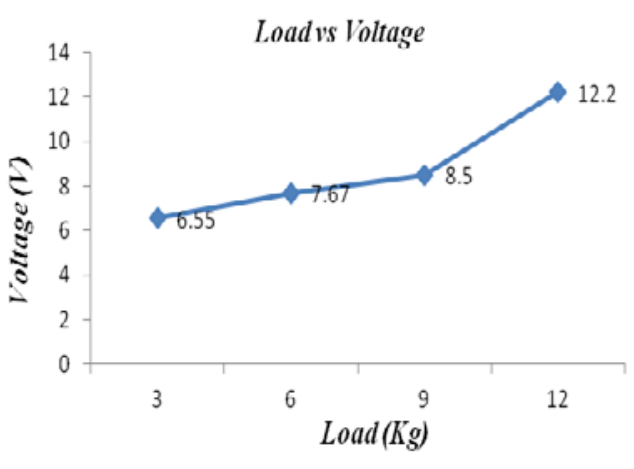

(b)

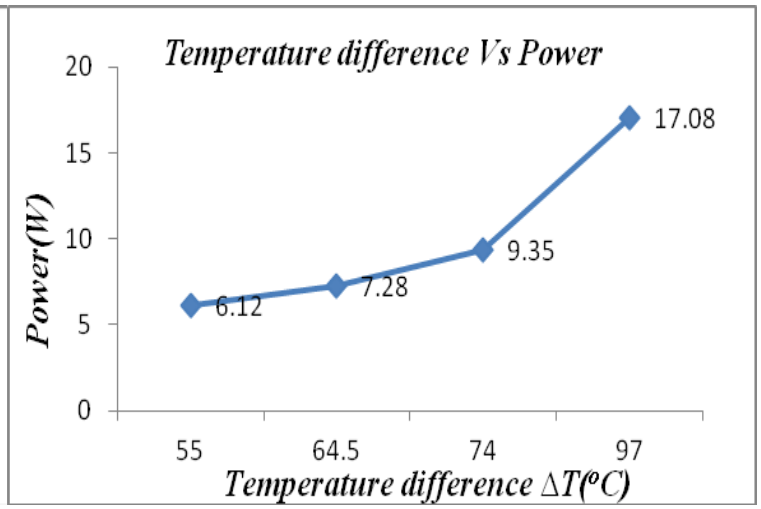

(d)

Figure 5. (a) Load Vs Power (b) Load Vs Voltage (c) Load Vs Current (d) Temperature difference Vs Power

The above graphs shows that if the load increases then thermoelectric power, voltage and current is also increases as shown in figure 5 . Hence the power, voltage and current are proportional to laod on the engine. Also if temperature difference between hot and cold side of the thermoelectric generator is increases then power also increases as shown in figure 5.

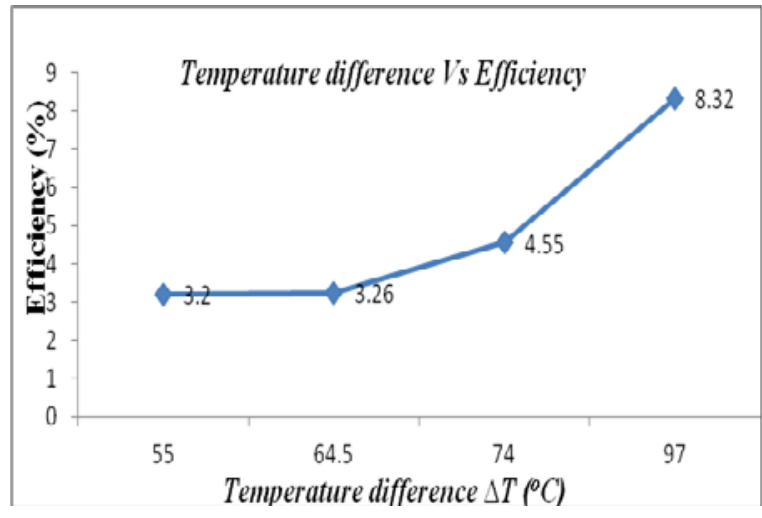

(a)

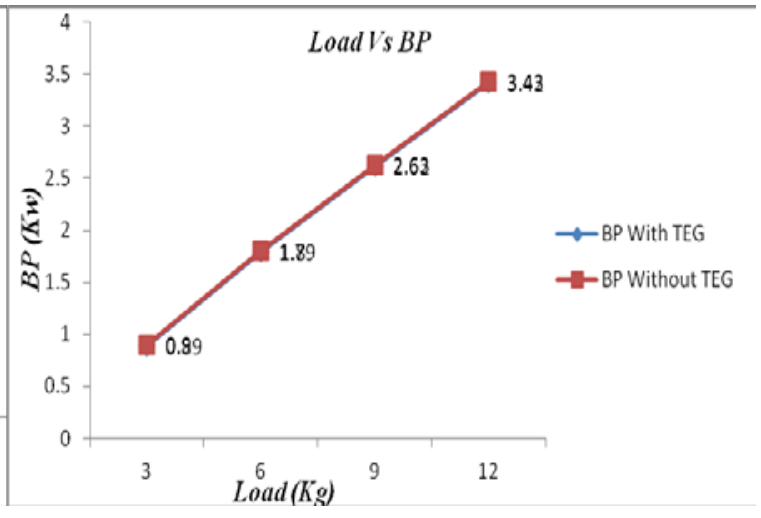

(b) 


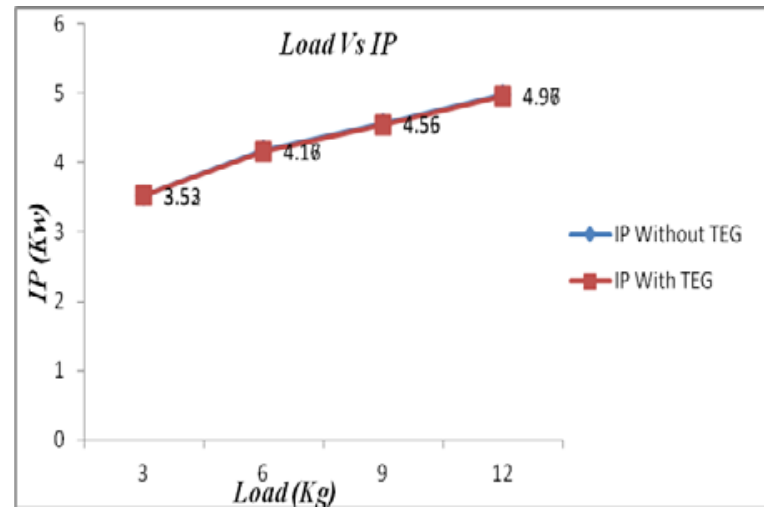

(c)

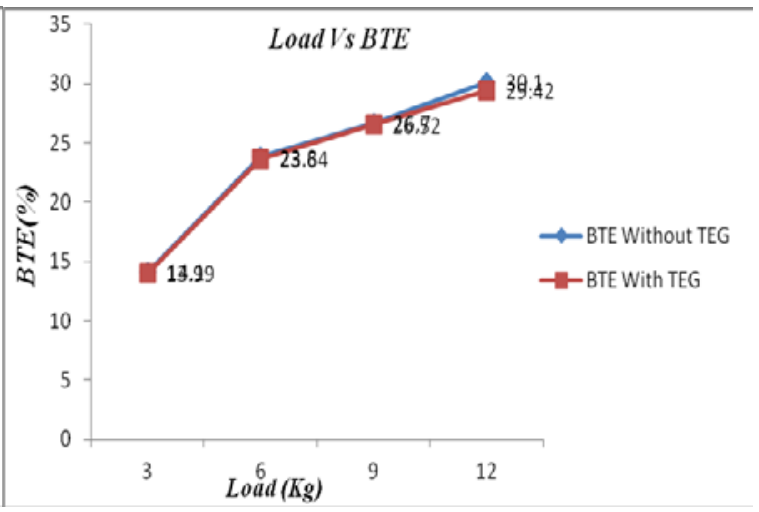

(d)

Figure 6. (a) Temperature difference Vs Efficiency (b) Load Vs Break power (c) Load Vs Indicated power (d) Load Vs Break thermal efficiency

If the temperature difference between hot side and cold side of thermoelectric generator is increases then efficiency of thermoelectric generator is also increases as shown in figure 6.The performance factors of engine break power, indicated power and break thermal efficiency are slightly decreased with thermoelectric generator as shown in figure 6.

Table -1 Experiment Result

\begin{tabular}{|c|c|c|c|}
\hline $\begin{array}{c}\text { Sr. } \\
\text { No. }\end{array}$ & $\begin{array}{c}\text { Temperature difference } \\
\text { between hot and cold side } \\
\Delta \mathbf{T}\left(\mathbf{~}^{\mathbf{}} \mathbf{C}\right)\end{array}$ & $\begin{array}{c}\text { Power } \\
\text { output } \mathbf{P} \\
\mathbf{( W )}\end{array}$ & $\begin{array}{c}\text { Efficiency } \\
\mathbf{( \% )}\end{array}$ \\
\hline 1. & 55 & 6.12 & 3.2 \\
\hline 2. & 64.5 & 7.28 & 3.26 \\
\hline 3. & 74 & 9.35 & 4.55 \\
\hline 4. & 97 & 17.08 & 8.32 \\
\hline
\end{tabular}

Table -2 Experiment Result

\begin{tabular}{|c|c|c|c|c|c|c|}
\hline \multirow{2}{*}{ Load(Kg) } & \multicolumn{3}{|c|}{ Without TEG } & \multicolumn{3}{c|}{ With TEG } \\
\cline { 2 - 7 } & BP(Kw) & IP(Kw) & BTE & BP(Kw) & IP(Kw) & BTE \\
\hline 3 & 0.90 & 3.53 & 14.1 & 0.89 & 3.52 & 13.99 \\
\hline 6 & 1.18 & 4.17 & 23.8 & 1.79 & 4.16 & 23.64 \\
\hline 9 & 2.63 & 4.56 & 26.7 & 2.62 & 4.55 & 26.52 \\
\hline 12 & 3.43 & 4.97 & 30.1 & 3.42 & 4.96 & 29.42 \\
\hline
\end{tabular}

Table 1 show the temperature difference between hot side and cold side of thermoelectric generator, power output and efficiency of thermoelectric generator. Table 2 shows the performance factors of engine break power, indicated power and break thermal efficiency with and without thermoelectric generator.

\section{IV.CONCLUSION}

1. Results show that voltage, current, power developed and efficiency of the system increase with the increase in Engine load, exhaust temperature \& flow rate of cooling water. 
2. With variation in load it is observed that if load increases the power, voltage, current and efficiency of thermoelectric generator is increased.

3. With variation in load we got maximum power of $17.08 \mathrm{~W}$, voltage $12.2 \mathrm{~V}$, current $1.4 \mathrm{~A}$ and efficiency $8.32 \%$ at load $12 \mathrm{Kg}$.

4. If temperature difference between hot side and cold side of thermoelectric generator is increased then efficiency is also in increased.

5. The performance factors of engine break power, indicated power and break thermal efficiency are slightly decreased with thermoelectric generator.

\section{REFERENCES}

[1] Basel I.I and Wael H. A, “Thermoelectric power generation using waste heat as an alternative green technology,” Recent patents on electrical engineering, 2(1), pp.27-29. 2009.

[2] Ramesh Kumar, Ankit Sonthalia, And Rahul Goel, "Experimental study on waste heat recovery from an internal combustion engine using thermoelectric technology,” thermal science, vol. 15, no. 4, pp. 1011-1022, 2011.

[3] Vázquez, J., et al., State of the Art of Thermoelectric Generators Based on Heat Recovered from the Exhaust Gases of Automobiles, Proceedings, 7th European Workshop on Thermoelectrics, Paper 17, Pamplona, Spain, 2002

[4] Madhav, A. K., et al., Thermoelectrical Energy Recovery from the Exhaust of a Light Truck, Proceedings, 2003 Diesel Engine Emissions Reduction Conference, Newport, R. I., USA, 2003

[5] Thacher, E. F., et al., Testing of an Automobile Exhaust Thermoelectric Generator in a Light Truck, Proceedings, Automobile Engineering, IMECHE, Vol. 221 Part D, 2007

[6] Patil D. and Arakerimath R. R., "A review of thermoelectric generator for waste heat recovery from engine exhaust,"

International Journal of research in aeronautical and mechanical engineering, 1(8), pp.1-9, 2013 